\title{
Color Doppler ultrasound characteristics after subinguinal microscopic varicocelectomy
}

\author{
Murat Akand ${ }^{1}$, Mustafa Koplay ${ }^{2}$, Necat Islamoglu ${ }^{2}$, Emre Altintas ${ }^{1}$, Ozcan Kilic ${ }^{1}$, Murat Gul', \\ Haluk Kulaksizoglu ${ }^{3}$, Mesut Sivri², Serdar Goktas ${ }^{1}$
}

${ }^{1}$ Selcuk University, School of Medicine, Department of Urology, Konya, ${ }^{2}$ Selcuk University, School of Medicine, Department of Radiology, Konya, ${ }^{3}$ Bilim University, Sisli Florence Nightingale Hospital, Department of Urology, Istanbul, Turkey

\begin{abstract}
Aim: The present study evaluated the effect of differences in the peak systolic velocity (PSV) and resistive index (RI) in the testicular artery (TA), capsular artery (CA), and intratesticular artery (ITA) after microscopic subinguinal varicocelectomy (MSV) on postoperative pain and semen parameters. Patients and methods: Scrotal color Doppler ultrasound (CDUS) measurements were made in 33 patients (age 18-31 years) prior to MSV and 3 and 6 months after MSV. Pain was recorded using a visual analog scale and sperm concentration was determined to analyze the predictive value of the CDUS parameters regarding surgical outcome. Results: A significant decrease in pain scores was observed in most patients at both follow-ups. The first postoperative CDUS revealed a significant increase in the TA-PSV $(p<0.001)$ and a decrease in the TA-RI $(p=0.002)$ and CA$\mathrm{RI}(\mathrm{p}=0.006)$. The second postoperative CDUS also revealed a significant increase in the TA-PSV and a decrease in the TA-RI, and the PSV in the ITA and CA and RI in the ITA and CA were significantly different from the values obtained pre-operatively and at the first follow-up. A negative correlation was found between the pain level and TA-PSV $(\mathrm{r}=-0.433$, $\mathrm{p}=0.012)$, whereas sperm concentration positively correlated with both the TA-PSV and CA-PSV $(r=0.534, p=0.001$ and $r=0.455, p=0.008$, respectively). Conclusions: The PSV and RI are useful parameters for detecting changes in testicular microhemodynamics after MSV. In addition, the TA-PSV and CA-PSV can be used to predict improvements in pain and sperm concentration.
\end{abstract}

Keywords: varicocele, pain, infertility, microscopic varicocelectomy, color Doppler ultrasound.

\section{Introduction}

Varicocele is a hemodynamic impairment with continuous blood reflux in the pampiniform venous plexus. The condition is characterized by abnormal dilatation and retrograde blood flow in the affected veins [1] and is present in approximately $15 \%$ of the general population. The prevalence is up to $35 \%$ in male population with primary infertility and can be as high as $75 \%$ in men with secondary infertility [2]. Although the effects of varicocele, in-

Received 20.06.2016 Accepted 30.08.2016

Med Ultrason

2017, Vol. 19, No 1, 59-65

Corresponding author: Murat Akand, MD, FEBU

Selçuk Üniversitesi, Alaeddin Keykubat Kampüsü, Tip Fakültesi Hastanesi, E-Blok, Kat:1, Üroloji Polikliniği, 42075 KampüsSelçuklu/Konya/Türkiye

Phone: +90 53274383 33, Fax: +90 3322412184

E-mail: drmuratakand@yahoo.com cluding a reduced volume of the affected testis, impaired sperm production, reduced fertility, and scrotal pain, are well established, the mechanism of testicular damage is still unclear [3]. The most accepted pathophysiology of varicocele-associated infertility is increased testicular temperature secondary to venous reflux [4].

Varicocelectomy can be performed by traditional open surgery (high retroperitoneal, inguinal, or subinguinal), microscopic surgery (inguinal or subinguinal), and laparoscopic approach. Regardless of different modalities, changes in semen parameters have been demonstrated. Cayan et al [5] found an improvement in the quality of spermatozoa in approximately $70 \%$ of patients, whereas another randomized controlled trial and a metaanalysis showed that varicocelectomy improves semen quality and reduces seminal oxidative stress [6,7]. In contrast, Evers et al [8] demonstrated that varicocelectomy is not effective for the treatment of male subfertility. Furthermore, Daitch et al [9] concluded that, although 
varicocelectomy did not improve semen parameters, it improved the chance of pregnancy and live birth rates in couples with male infertility that underwent intrauterine insemination.

The testes are supplied by three major arteries: the testicular artery (TA), the cremasteric artery, and the deferential artery. The TA divides into two branches; the capsular artery (CA) that continues on the surface of the testis and the intratesticular artery (ITA) that goes deep into the parenchyma of the testis [10]. Scrotal color Doppler ultrasound (CDUS) has been established as an effective and accurate diagnostic tool for examining the macro and microvascularity of the testes, in which arterial flow velocities (peak systolic velocity [PSV] and end-diastolic velocity [EDV]) and resistance indices (e.g., resistive index [RI] and pulsatility index [PI]) can be easily measured [10-12].

In this study, we evaluated the effect of differences in the PSV and RI in the TA, CA, and ITA before and after microscopic subinguinal varicocelectomy (MSV) on postoperative pain and semen parameters.

\section{Materials and methods}

This study was reviewed and approved by the Selcuk University School of Medicine Ethics Committee (approval 2012/97) and performed in accordance with the ethical standards in the 1964 Declaration of Helsinki and its later amendments. Written informed consent was obtained from all patients.

The aim of the study was to evaluate whether the PSV and/or RI can be used to predict surgical outcomes in regards to the pre-operative pain level and semen parameters. Therefore, the PSV and RI were measured in three different levels of arterial supply (i.e., the TA, CA, and ITA) before and after MSV to identify correlations between these CDUS parameters and decreased pain and/ or improved semen parameters.

Between June 2012 and March 2015, 82 men were diagnosed with clinical varicocele. Fifty-nine of these patients underwent a left MSV and 11 underwent a bi- lateral MSV in our department. The exclusion criteria for this study were bilateral varicocele, any scrotal pathology other than varicocele, and a history of previous varicocelectomy. Thus, a total of 38 patients who had a left varicocele presenting only with left scrotal pain and infertility/abnormal semen parameters were included in this prospective study. No comorbidities, including hypertension, diabetes, or other general diseases, were present in these patients.

The physical examination was performed in a warm room and the Valsalva maneuver was performed while the patient was standing upright [4]. The degree of varicocele was graded clinically as grade I (varicocele palpable only during Valsalva maneuver), grade II (varicocele palpable in standing position), and grade III (varicocele detectable by visual scrutiny alone) [4]. Pain was evaluated by a 10-point visual analog scale (VAS) in which 0 was graded as no pain and 10 as the worst pain in the patient's life. Before the operation, two separate semen analyses were performed with an interval of at least 2 weeks on samples obtained via masturbation after 3-5 days of sexual abstinence. The sperm concentration and motility were assessed using the World Health Organization (WHO) 2010 guidelines [13].

Before surgery, all patients underwent CDUS performed by the same radiologist (M.K.) using color and Duplex ultrasonography (Toshiba Aplio 400, Tokyo, Japan) with a linear $7.5 \mathrm{MHz}$ transducer in the supine position. During the examination, the diameter of the largest vein in the pampiniform plexus, the retrograde flow in both the relaxed state and during the Valsalva maneuver, and the PSV and RI of the TA, CA, and ITA were measured (fig 1). The presence of two or more varicose veins with a diameter of at least $3 \mathrm{~mm}$ and a retrograde flow lasting more than 2 seconds during the Valsalva maneuver were the diagnostic criteria defining a clinical varicocele.

All of the patients underwent a left MSV under spinal or general anesthesia by the same surgeon (M.A.). Using an operating microscope (Carl Zeiss $\left.{ }^{\mathbb{R}}\right)$ at 15-20x magnification, all internal spermatic veins were identified,

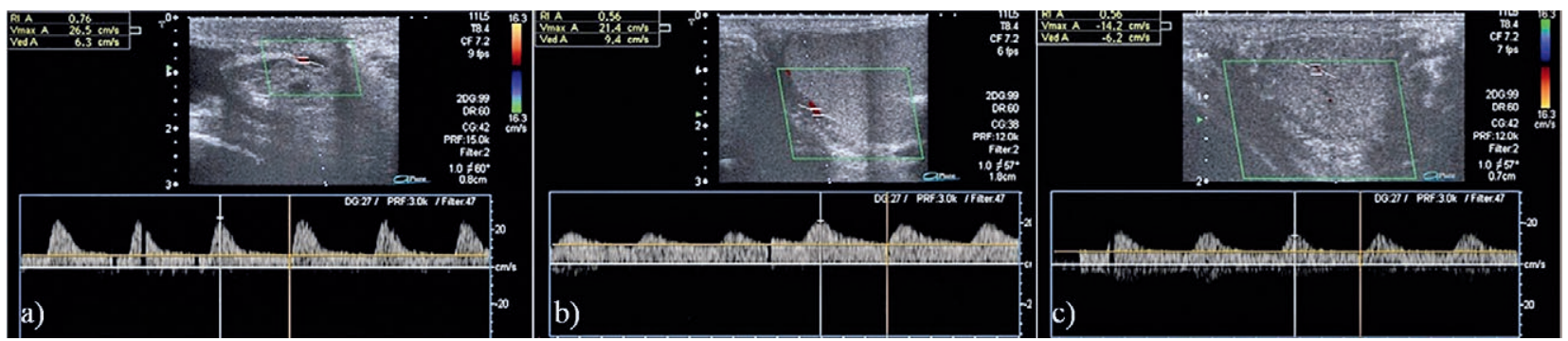

Fig 1. CDUS image showing the measurement of the peak systolic velocity (PSV) and resistive index (RI) in a) at pretesticular level: testicular artery (TA), b) at capsular level: capsular artery (CA), and c) at intratesticular level: intratesticular artery (ITA). 
dissected, and ligated with 3-0 silk sutures and then divided while preserving vas deferens, vassal vessels, TA, and lymphatic vessels as much as possible. Patients were examined carefully for an external spermatic vein; if present it was also ligated and divided. All patients were discharged the day after surgery without any peri-operative complications.

All patients were scheduled for a follow-up at 3 and 6 months to evaluate pain and to perform a semen analysis and scrotal CDUS. Complications, such as hydrocele and testicular atrophy, were also examined during the follow-up.

Patients were classified into four groups according to their VAS scores: no (0), mild (1-4), moderate (5-6), and severe (7-10) pain [14]. An at least 3-point decrease in the VAS score or no pain at all at 6 months was defined as successful pain improvement. Patients were also considered to have had a successful or failed operation based on sperm concentration $(\geq 15$ million $/ \mathrm{mL}$ and $<15$ million/ $\mathrm{mL}$, respectively) [13].

\section{Statistical analysis}

The normality of the distributions was evaluated using the Shapiro-Wilk test. Wilcoxon, paired t, MannWhitney U, and Friedman tests were used to test the differences between group numbers and paired or unpaired groups as appropriate. The results were expressed as mean \pm standard deviation, median (min-max), or number (frequency). The Spearman rho correlation coefficient was used to indicate relationships between variables. The significance level $(\alpha)$ was 0.05 and a twotailed $\mathrm{p}<0.05$ was considered significant. All statistical analyses were performed using SPSS 15.0 (SPSS Inc., Chicago, IL, USA).

\section{Results}

Postoperative data were missing for 2 patients at the first follow-up and 3 patients at the second follow-up; therefore, 33 patients were evaluated in the final analysis. The mean age was $25.5 \pm 4.5$ years (median 26 years, range 18-31 years). Nineteen patients (57.6\%) had grade II and 14 patients (42.4\%) grade III varicocele. During MSV, the median number of ligated veins was 9 (range $4-12$ ), and 20 patients (60.6\%) had an external spermatic vein. The mean duration of MSV was $72.4 \pm 14.6 \mathrm{~min}$ (range 50-118 min). No patient had hydrocele or testicular atrophy during the follow-up. Pre-operative and postoperative pain scores, sperm parameters, vein diameters, and the PSV and RI of the TA, CA, and ITA are reported in Table I.

A significant decrease in pain scores was observed in the majority of patients at both follow-ups. Only four patients did not have improved pain scores. Based on the sperm concentrations at 6 months, 21 patients $(63.6 \%)$ had a successful operation. Scrotal CDUS at 3 months revealed a significant increase in the TA-PSV and a significant decrease in the TA-RI and CA-RI. However, CDUS at 6 months revealed a significant increase in the TA-PSV and a decrease in the TA-RI compared to the pre-operative value. However, the PSV of the ITA and CA significantly increased and the RI of the ITA and CA significantly decreased with respect to both the pre-operative and 3-month values.

At the first follow-up, a significant positive correlation was observed between the TA-PSV and ITA-PSV $(\mathrm{r}=0.358, \mathrm{p}=0.04)$, TA-PSV and CA-PSV $(\mathrm{r}=0.469$, $\mathrm{p}=0.006)$, and ITA-PSV and CA-PSV $(\mathrm{r}=0.46, \mathrm{p}=0.007)$.

Table I. Preoperative and postoperative (at 3 and 6 months) pain scores, sperm parameters, vein diameters, and scrotal CDUS parameters of the patients $(\mathrm{n}=33)$.

\begin{tabular}{|c|c|c|c|c|c|}
\hline \multicolumn{2}{|c|}{ Parameters } & Preoperative & Postoperative-1 ( $3^{\text {rd }}$ month) & Postoperative-2 (6 ${ }^{\text {th }}$ month) & p value \\
\hline \multicolumn{2}{|c|}{ Pain (VAS score) } & $6.0 \pm 1.9$ & $2.2 \pm 1.4^{*}$ & $1.6 \pm 1.4 *+$ & $<0.001$ \\
\hline \multicolumn{2}{|c|}{ Concentration (million $/ \mathrm{mL}$ ) } & $8.5 \pm 6.3$ & $32.6 \pm 33.7 *$ & $36.2 \pm 33.8 * \$$ & $<0.001$ \\
\hline \multicolumn{2}{|c|}{ Motility (\%) } & $54.3 \pm 27.7$ & $69.9 \pm 19.7 *$ & $70.5 \pm 20.1^{*}$ & $<0.001$ \\
\hline \multicolumn{2}{|c|}{ Vein Diameter (mm) } & $3.6 \pm 0.8$ & $2.9 \pm 0.9 *$ & $2.7 \pm 0.8 * \#$ & $<0.001$ \\
\hline \multirow[t]{2}{*}{ TA } & $\mathrm{PSV}(\mathrm{cm} / \mathrm{sec})$ & $9.4 \pm 1.9$ & $11.4 \pm 3.8^{* *}$ & $11.5 \pm 3.5 \S$ & $<0.001$ \\
\hline & RI & $0.69 \pm 0.12$ & $0.62 \pm 0.11^{*}$ & $0.61 \pm 0.11^{*}$ & $<0.001$ \\
\hline \multirow[t]{2}{*}{ ITA } & $\mathrm{PSV}(\mathrm{cm} / \mathrm{sec})$ & $6.9 \pm 2.3$ & $7.4 \pm 2.5$ & $7.8 \pm 2.8 ¥ \dagger \dagger$ & 0.011 \\
\hline & RI & $0.57 \pm 0.08$ & $0.54 \pm 0.09$ & $0.51 \pm 0.08 \S €$ & 0.005 \\
\hline \multirow[t]{2}{*}{$\mathrm{CA}$} & $\mathrm{PSV}(\mathrm{cm} / \mathrm{sec})$ & $8.2 \pm 2.1$ & $8.9 \pm 2.6$ & $9.5 \pm 2.7 *+t$ & $<0.001$ \\
\hline & RI & $0.63 \pm 0.09$ & $0.58 \pm 0.09 \dagger$ & $0.55 \pm 0.09 \S \Phi$ & $<0.001$ \\
\hline
\end{tabular}

Data are given in mean \pm SD. CDUS: Color Doppler ultrasound, SD: Standard deviation, VAS: Visual analog scale, TA: Testicular artery, ITA: Intratesticular artery, CA: Capsular artery, PSV: Peak systolic velocity, RI: Resistive index. * $\mathrm{p}<0.001$, comparison with preoperative, Wilcoxon test; $* * \mathrm{p}=0.002$, comparison with preoperative, paired-t test; $\dagger \mathrm{p}=0.006$, comparison with preoperative, paired-t test; $\S \mathrm{p}<0.001$, comparison with preoperative, paired-t test; $¥ \mathrm{p}=0.007$, comparison with preoperative, Wilcoxon test; $\$ \mathrm{p}=0.003$, comparison with postoperative-1, Wilcoxon test; $\$ \mathrm{p}<0.001$, comparison with postoperative-1, Wilcoxon test; $\# \mathrm{p}=0.024$, comparison with postoperative-1, Wilcoxon test; $\dagger \dagger \mathrm{p}=0.014$, comparison with postoperative- 1 , Wilcoxon test; $€ \mathrm{p}=0.006$, comparison with postoperative- 1 , Wilcoxon test; $+t \mathrm{p}=0.003$, comparison with postoperative-1, paired-t test; $\uparrow \mathrm{p}=0.017$, comparison with postoperative-1, paired-t test 
A negative correlation was found between the PSV and RI of the TA $(r=-0.49, p=0.004)$, ITA $(r=-0.67, p<0.001)$, and CA $(r=-0.64, p<0.001)$. Although the TA-RI did not correlate with any of these parameters, the ITA-RI positively correlated with the CA-RI $(r=0.597, \mathrm{p}<0.001)$. The negative correlation between the PSV and RI of the TA and ITA continued to exist between the first and second follow-up $(r=-0.446, p=0.009$ and $r=-0.354, p=0.043$, respectively).

The correlations between the 6-month values and pre-operative values provided much more information about the results of the operation. A negative correlation was found between the pain level and TA-PSV $(r=-0.433$, $\mathrm{p}=0.012$ ), whereas sperm concentration positively correlated with both the TA-PSV $(r=0.534, p=0.001)$ and CAPSV ( $r=0.455, p=0.008)$. The negative correlation found between the sperm concentration and pain $(\mathrm{r}=-0.476$, $\mathrm{p}=0.005$ ) might indicate that the operation was successful in terms of both pain relief and sperm concentration. All other correlations between CDUS parameters, except between the TA-RI and ITA-PSV, were significant (Table II). The increase in the PSV ofn the TA, ITA, and CA and the decrease in the RI of the TA, ITA, and CA were still present at 6 months. Therefore, the positive correlations between these values and the negative correlation between the PSV and RI in these three arteries were maintained.

No differences were observed in the CDUS parameters, except the TA-RI, between patients with or without successful pain relief, ( 0.62 vs. 0.50 , respectively; $p=0.047$ ). As the $p$-value was very close to the cut-off, this relationship can be ignored (Table III). When the patients with a successful or failed operation in terms of sperm concentration were evaluated, significant differences were observed only in the PSV of the ITA and CA at the first follow-up, and in the PSV of the TA and CA at the second follow-up (Table IV).

Table II. Correlations within CDUS parameters at 6 months after surgery.

\begin{tabular}{|c|c|c|c|c|c|c|c|}
\hline & & TA-PSV & TA-RI & ITA-PSV & ITA-RI & CA-PSV & CA-RI \\
\hline TA-PSV & $\begin{array}{l}\mathrm{r} \\
\mathrm{p}\end{array}$ & 1 & $\begin{array}{l}-0.696 \\
<0.001\end{array}$ & $\begin{array}{l}0.462 \\
0.007\end{array}$ & $\begin{array}{l}-0.363 \\
0.038\end{array}$ & $\begin{array}{l}0.758 \\
<0.001\end{array}$ & $\begin{array}{l}-0.394 \\
0.023\end{array}$ \\
\hline TA-RI & $\begin{array}{l}\mathrm{r} \\
\mathrm{p}\end{array}$ & & $\begin{array}{l}1 \\
.\end{array}$ & $\begin{array}{l}-0.177 \\
0.323\end{array}$ & $\begin{array}{l}0.508 \\
0.003\end{array}$ & $\begin{array}{l}-0.588 \\
<0.001\end{array}$ & $\begin{array}{l}0.606 \\
<0.001\end{array}$ \\
\hline ITA-PSV & $\begin{array}{l}\mathrm{r} \\
\mathrm{p}\end{array}$ & & & $\begin{array}{l}1 \\
.\end{array}$ & $\begin{array}{l}-0.598 \\
<0.001\end{array}$ & $\begin{array}{l}0.618 \\
<0.001\end{array}$ & $\begin{array}{l}-0.367 \\
0.036\end{array}$ \\
\hline ITA-RI & $\begin{array}{l}\mathrm{r} \\
\mathrm{p}\end{array}$ & & & & $\begin{array}{l}1 \\
.\end{array}$ & $\begin{array}{l}-0.487 \\
0.004\end{array}$ & $\begin{array}{l}0.456 \\
0.008\end{array}$ \\
\hline CA-PSV & $\begin{array}{l}\mathrm{r} \\
\mathrm{p}\end{array}$ & & & & & $\begin{array}{l}1 \\
.\end{array}$ & $\begin{array}{l}-0.575 \\
<0.001\end{array}$ \\
\hline CA-RI & $\begin{array}{l}\mathrm{r} \\
\mathrm{p}\end{array}$ & & & & & & $\begin{array}{l}1 \\
.\end{array}$ \\
\hline
\end{tabular}

CDUS: Color Doppler ultrasound, TA: Testicular artery, TA: Intratesticular artery, CA: Capsular artery, PSV: Peak systolic velocity, RI: Resistive index.

Table III. Preoperative and postoperative (at 3 and 6 months) scrotal CDUS parameters of the patients with or without success in pain relief $(n=33)$.

\begin{tabular}{|c|c|c|c|c|c|c|c|c|c|c|}
\hline & & \multicolumn{3}{|c|}{ Preoperative } & \multicolumn{3}{|c|}{ Postoperative-1 (at 3 months) } & \multicolumn{3}{|c|}{ Postoperative-2 (at 6 months) } \\
\hline \multicolumn{2}{|c|}{ Parameters } & $\begin{array}{l}\text { No Success } \\
(n=4)\end{array}$ & $\begin{array}{l}\text { Success } \\
(n=29)\end{array}$ & p value & $\begin{array}{l}\text { No Success } \\
(n=4)\end{array}$ & $\begin{array}{l}\text { Success } \\
(n=29)\end{array}$ & p value & $\begin{array}{l}\text { No Success } \\
(n=4)\end{array}$ & $\begin{array}{l}\text { Success } \\
(n=29)\end{array}$ & p value \\
\hline \multirow[t]{2}{*}{ TA } & PSV & $9.1 \pm 2.5$ & $9.4 \pm 1.8$ & 0.890 & $7.9 \pm 4.5$ & $11.9 \pm 3.5$ & 0.116 & $9.1 \pm 5.5$ & $11.8 \pm 3.2$ & 0.392 \\
\hline & RI & $0.58 \pm 0.20$ & $0.71 \pm 0.10$ & 0.143 & $0.53 \pm 0.17$ & $0.63 \pm 0.09$ & 0.224 & $0.50 \pm 0.15$ & $0.62 \pm 0.10$ & 0.047 \\
\hline \multirow[t]{2}{*}{ ITA } & PSV & $8.0 \pm 3.7$ & $6.7 \pm 2.1$ & 0.699 & $7.7 \pm 4.1$ & $7.3 \pm 2.3$ & 0.825 & $8.3 \pm 4.1$ & $7.8 \pm 2.6$ & 1.000 \\
\hline & RI & $0.61 \pm 0.06$ & $0.57 \pm 0.08$ & & $0.55 \pm 0.02$ & $0.54 \pm 0.09$ & 0.803 & $0.53 \pm 0.07$ & $0.51 \pm 0.08$ & 0.489 \\
\hline \multirow[t]{2}{*}{$\mathrm{CA}$} & PSV & $6.9 \pm 0.9$ & $8.4 \pm 2.2$ & 0.129 & $7.9 \pm 1.8$ & $9.1 \pm 2.6$ & 0.508 & $7.6 \pm 2.0$ & $9.8 \pm 2.7$ & 0.092 \\
\hline & RI & $0.62 \pm 0.09$ & $0.63 \pm 0.10$ & 0.890 & $0.55 \pm 0.11$ & $0.59 \pm 0.09$ & 0.490 & $0.54 \pm 0.08$ & $0.55 \pm 0.09$ & 0.699 \\
\hline
\end{tabular}

CDUS: Color Doppler ultrasound, TA: Testicular artery, ITA: Intratesticular artery, CA: Capsular artery, PSV: Peak systolic velocity, RI: Resistive index. All values are given as mean $\pm \mathrm{SD}$. 
Table IV. Preoperative and postoperative (at 3 and 6 months) scrotal CDUS parameters of the patients with or without success in sperm concentration $(n=33)$.

\begin{tabular}{|c|c|c|c|c|c|c|c|c|c|}
\hline & \multicolumn{3}{|c|}{ Preoperative } & \multicolumn{3}{|c|}{ Postoperative-1 (at 3 months) } & \multicolumn{3}{|c|}{ Postoperative-2 (at 6 months) } \\
\hline Parameters & $\begin{array}{l}\text { No Success } \\
(n=12)\end{array}$ & $\begin{array}{l}\text { Success } \\
(n=21)\end{array}$ & p value & $\begin{array}{l}\text { No Success } \\
(n=12)\end{array}$ & $\begin{array}{l}\text { Success } \\
(n=21)\end{array}$ & p value & $\begin{array}{l}\text { No Success } \\
(n=12)\end{array}$ & $\begin{array}{l}\text { Success } \\
(n=21)\end{array}$ & p value \\
\hline PSV & $9.1 \pm 1.7$ & $9.5 \pm 2.0$ & 0.488 & $10.3 \pm 5.2$ & $11.9 \pm 2.7$ & 0.314 & $9.2 \pm 3.8$ & $12.8 \pm 2.7$ & 0.003 \\
\hline RI & $0.69 \pm 0.17$ & $0.70 \pm 0.09$ & 0.822 & $0.62 \pm 0.15$ & $0.61 \pm 0.08$ & 0.549 & $0.63 \pm 0.15$ & \pm 0.09 & 0.261 \\
\hline PSV & $6.6 \pm 1.5$ & $7.1 \pm 2.7$ & 0.925 & $6.2 \pm 1.7$ & $8.0 \pm 2.7$ & 0.034 & 2.1 & $8.3 \pm 3.0$ & 0.359 \\
\hline RI & $0.55 \pm 0.09$ & $0.58 \pm 0.07$ & & $0.58 \pm 0.09$ & $0.53 \pm 0.08$ & 0.237 & $0.49 \pm 0.08$ & $0.52 \pm 0.08$ & 0.388 \\
\hline PSV & $7.4 \pm 1.8$ & $8.7 \pm 2.3$ & 0.075 & $7.1 \pm 1.7$ & $10.0 \pm 2.4$ & $<0.001$ & $7.3 \pm 2.0$ & $10.8 \pm 2.2$ & $<0.001$ \\
\hline RI & $0.61 \pm 0.09$ & $0.64 \pm 0.10$ & 0.512 & $0.61 \pm 0.10$ & $0.57 \pm 0.08$ & 0.166 & $0.56 \pm 0.12$ & $0.55 \pm 0.07$ & 0.561 \\
\hline
\end{tabular}

CDUS: Color Doppler ultrasound, TA: Testicular artery, ITA: Intratesticular artery, CA: Capsular artery, PSV: Peak systolic velocity, RI: Resistive index. All values are given as mean $\pm \mathrm{SD}$.

\section{Discussions}

Varicocele is a common entity in daily urological practice, especially in infertile men. Though the disorder may be completely asymptomatic, scrotal pain and/ or fertility problems can occur. CDUS is a useful and non-invasive tool for the diagnosis and follow-up of varicocele and has a sensitivity of $83-95 \%[15,16]$. The technique helps measure the testicular dimensions, the diameters of dilated veins, the retrograde flow, and the arterial flow parameters, such as the PSV, EDV, RI, and PI. The effects of varicocelectomy on semen parameters and on pregnancy rates are well studied, but relatively little is known about the changes in the microvasculature of the testicles after surgery [5-9]. A few years ago, different research groups evaluated the microhemodynamics of the testes after varicocelectomy and reported different results $[17,18]$. The changes in the microhemodynamics of the testes recently became a hot topic yet again, with some authors trying to find a correlation between CDUS parameters and surgical outcomes. We aimed to identify a CDUS parameter that can help predict pain reduction and/or improved semen parameters.

Tanriverdi et al observed no change in the maximal and minimal flow rates or the RI after microsurgical and high ligation varicocelectomy, concluding that no significant impairment of testicular circulation occurred after surgery [17]. Unsal et al found a significant difference in the RI and PI of the CA in varicocele patients compared to a control group [18]. Keeping in mind that there was a small number of cases in their study, the authors pointed out that these indices may be an indicator of impaired testicular microcirculation. Later, Balci et al were the first to show a significant decrease in the mean intratesticular RI with an improvement in semen parameters and concluded that a decrease in the RI suggests an improvement in the testicular blood supply [11]. However, they did not find a correlation between the difference in the RI and an improvement in the total motile sperm count, probably because of the small number of patients.

Tarhan et al investigated the long-term effects of inguinal MVS on blood flow and semen parameters [12]. The PSV and EDV were increased in the left TA, and the RI and PI of the left CA and ITA were decreased, but the authors did not observe any change in these parameters in the right arteries. They also found a significant correlation between the semen analysis and the PSV, RI, and PI of the left CA [12]. With a significant correlation between improved testicular hemodynamics and semen parameters, the authors suggested that testicular blood flow parameters could be used in the postoperative follow-up of patients with varicocele.

Two very recent studies correlated improvements in testicular blood flow parameters and semen analysis. Zhang et al showed that the PSV, RI, and PI of the left CA and ITA decreased significantly after laparoscopic varicocelectomy and MSV, but no significant difference was noted in the EDV [19]. Separately evaluating these differences for the two approaches, the authors found that MSV provided a better and earlier improvement in these parameters. They also concluded that the RI and PI of the ITA and CA are two important indices for predicting the prognosis after varicocelectomy. Ener et al evaluated the arterial flow, resistance, and sperm parameters before and 3 months after subinguinal varicocelectomy [20]. A significant increase in the PSV and EDV with a significant decrease in the PI and RI of the left CA correlated with a significant improvement in the sperm concentration, progressive motility, and morphology at 3 months. However, they were not able to show a significant difference in the CDUS parameters of patients with improved semen parameters compared to those without improved semen parameters, which they reasoned was due to the small number of patients in their study.

We observed a significant increase in the PSV of the TA, ITA, and CA, as well as a significant decrease in the 
RI of the same arteries. The changes in the PSV and RI of the TA were more prominent, which may be due to the wider diameter of this artery compared to the other two. Assessing the PSV and EDV in the CA and ITA is generally more difficult because these arteries are smaller and more tortuous and have a lower flow velocity. Moreover, evaluation of these blood flow parameters with CDUS depends on the angle of insonation and the vessel diameters, whereas the PI and RI do not depend on these factors [21].

Zhang et al evaluated only the CA and ITA 6 months after surgery, whereas we assessed the PSV and RI of the TA, CA, and ITA at 3 and 6 months after surgery [19]. Although the significant decrease in the RI of the CA and ITA was similar to their findings, we also observed an increase in the PSV in these arteries. Thus, our results are partly similar to those of Ener et al [20], though they only assessed the $\mathrm{CA}$ at 3 months. Tanriverdi et al assessed the RI at 7 days after varicocelectomy and failed to show any change [17]. The authors criticized themselves, as very early postoperative evaluation may not provide accurate information about testicular hemodynamics. Similar to Tarhan et al [12], we also think that late assessment of these parameters would provide more information about the microhemodynamics of the testes and the success of the operation because it may take several months for the edema and inflammation in the operative field to recover. We think that a greater number of significant correlations between the pre-operative and second postoperative values proves this hypothesis.

Our results show that improved pain levels, sperm parameters, and CDUS parameters continue up to 6 months after surgery. This improvement may likely continue after 6 months. The PSV in the three arteries continued to increase as the RI values decreased, which shows the ongoing changes in the microhemodynamics of the testes. The TA-PSV and CA-PSV seem to have the potential for use in predicting improvements in sperm concentration, whereas the TA-PSV can be used for pain relief.

When the differences in CDUS parameters between patients with successful and failed surgery in terms of both pain and sperm concentration were considered, a few parameters were found to have significant predictive value. The TA-PSV was significant when all patients were evaluated, but the TA-RI seemed to have value for predicting an improvement in pain in the subgroup assessment, though it was not significant and is not enough to conclude a firm correlation. The inclusion of relatively few patients may have had an effect on this result. When considering successful and failed surgery based on the sperm concentration, the PSV of the ITA and CA at 3 months and the PSV of the TA and CA at 6 months had the potential to predict the outcome. The CA-PSV was significant at both follow-ups. Taken together, the results indicate that the CA-PSV can be used to differentiate patients with successful surgeries based on sperm concentration.

This study has some limitations. First, a relatively small number of patients was enrolled in the study and 5 patients were lost to follow-up, which may have affected the statistical analysis. Second, sperm morphology was not evaluated due to missing data. Third, only the PSV and RI were measured on scrotal CDUS. Including the EDV and PI would have been beneficial.

Nonetheless, this study has some important strengths. Relatively young and healthy patients were evaluated, which made the study cohort quite homogenous. In addition, all patients were operated on by the same surgeon using a microsurgical technique, and all scrotal CDUSs were performed by the same radiologist and all spermiograms in the same laboratory. Moreover, two postoperative follow-ups were performed, which made the results more consistent and reliable.

\section{Conclusion}

Even with limited parameters, scrotal CDUS is a useful tool for detecting changes in the microhemodynamics of the testes after MSV and predicting the surgical outcome. The TA-PSV and CA-PSV can be used to predict improvements in pain and sperm concentration. Prospective controlled studies in larger cohorts are needed to understand whether the correlation of blood flow and resistance parameters with surgical outcomes is persistent in the long-term postoperative period and whether these parameters can be used routinely in clinical practice.

\section{Conflict of interest: none}

Acknowledgments: We would like to thank Mr. M. Bora Erdogdu for his valuable help with the statistical analysis. This project was funded by the Selcuk University Coordinatorship of Scientific Research Projects (BAP) (grant number 13401053).

\section{References}

1. Cimador M, Castagnetti M, Gattuccio I, Pensabene M, Sergio M, De Grazia E. The hemodynamic approach to evaluating adolescent varicocele. Nat Rev Urol 2012;9:247-257.

2. Goldstein M. Surgical management of male infertility. In: Wein A, Kavoussi LR, Novick AC, Partin AW, Peters CA. Editors. Campbell-Walsh Urology. Philadelphia, PA: Elsevier Saunders; 2012:648-687. 
3. Schauer I, Madersbacher S, Jost R, Hubner WA, Imhof M. The impact of varicocelectomy on sperm parameters: a meta-analysis. J Urol 2012;187:1540-1547.

4. Vanlangenhove P, Dhondt E, Everaert K, Defreyne L. Pathophysiology, diagnosis and treatment of varicoceles: a review. Minerva Urol Nefrol 2014;66:257-282.

5. Cayan S, Shavakhaov S, Kadioglu A. Treatment of palpable varicocele in infertile men: a meta-analysis to define the best technique. J Androl 2009;30:33-40.

6. Abdel-Meguid TA, Al-Sayyad A, Tayib A, Farsi HM. Does varicocele repair improve male infertility? An evidencebased perspective from a randomized, controlled trial. Eur Urol 2011;59:455-461.

7. Baazeem A, Belzile E, Ciampi A, et al. Varicocele and male factor infertility treatment: a new meta-analysis and review of the role of varicocele. Eur Urol 2011;60:796-808.

8. Evers JL, Collins JA. Assessment of efficacy of varicocele repair for male subfertility: a systematic review. Lancet 2003;361:1849-1852.

9. Daitch JA, Bedaiwy MA, Pasqualotto EB, et al. Varicocelectomy improves intrauterine insemination success rates in men with varicocele. J Urol 2001;165:1510-1513.

10. Pinggera GM, Mitterberger M, Bartsch G, et al. Assessment of the intratesticular resistive index by colour Doppler ultrasonography measurements as a predictor of spermatogenesis. BJU Int 2008;101:722-726.

11. Balci A, Karazincir S, Gorur S, Sumbas H, Egilmez E, Inandi $T$. Long-term effect of varicocele repair on intratesticular arterial resistance index. J Clin Ultrasound 2008;36:148-152.

12. Tarhan S, Ucer O, Sahin MO, Gumus B. Long-term effect of microsurgical varicocelectomy on testicular blood flow. J Androl 2011;32:33-39.
13. Cooper TG, Noonan E, von Eckardstein S, et al. World Health Organization reference values for human semen characteristics. Hum Reprod Update 2010;16:231-245.

14. Jensen MP, Chen C, Brugger AM. Interpretation of visual analog scale ratings and change scores: a reanalysis of two clinical trials of postoperative pain. J Pain 2003;4:407-414.

15. Schurich M, Aigner F, Frauscher F, Pallwein L. The role of ultrasound in assessment of male fertility. Eur J Obstet Gynecol Reprod Biol 2009;114(suppl 1):S192-S198.

16. El-Haggar S, Nassef S, Gadalla A, Latif A, Mostafa T. U1trasonographic parameters of the spermatic veins at the inguinal and scrotal levels in varicocele diagnosis and postoperative repair. Andrologia 2012;44:210-213.

17. Tanrıverdi O, Miroglu C, Horasanlı K, Altay B, Caliskan KC, Gumus E. Testicular blood flow measurements and mean resistive index values after microsurgical and high ligation varicocelectomy. Urology 2006;67:1262-1265.

18. Unsal A, Turgut AT, Taskin F, Kosar U, Karaman CZ. Resistance and pulsality index increase in capsular branches of testicular artery: indicator of impaired testicular microcirculation in varicocele? J Clin Ultrasound 2007;35:191-195.

19. Zhang M, Du L, Liu Z, Qi H, Chu Q. The effects of varicocelectomy on testicular arterial blood flow: laparoscopic surgery versus microsurgery. Urol J 2014;11:1900-1906.

20. Ener K, Ucgul YE, Okulu E, et al. Comparison of arterial blood supply to the testicles in the preoperative and early postoperative period in patients undergoing subinguinal varicocelectomy. Scand J Urol 2015;49:169-173.

21. Marchesini AC, Magrio FA, Berezowski AT, Neto OB, Nogueira AA, Candido dos Reis FJ. A critical analysis of Doppler velocimetry in the differential diagnosis of malignant and benign ovarian masses. J Womens Health (Larchmt) 2008;17:97-102 . 